\title{
Analisa Koordinasi Setting Proteksi Over Current Relay (OCR) Outgoing 20 kV dan Recloser pada Trafo II 60 MVA Feeder RBG 01 di Gardu Induk 150 kV Rembang
}

\author{
Indri Safitri' ${ }^{1)}$, Gunawan'), dan Agus Adhi Nugroho ${ }^{3)}$ \\ ${ }^{1,2,3)}$ Program Studi Teknik Elektro, Fakultas Teknologi Industri, Universitas Islam Sultan Agung Semarang \\ ${ }^{1,2,3)} \mathrm{Jl}$. Raya Kaligawe Km.4 Po.Box 1054 Semarang 50112

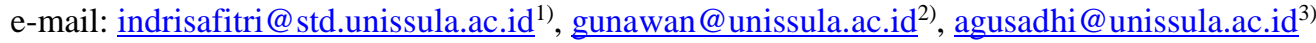

\begin{abstract}
According to energy observers from the Institute for Essential Services Reform (IESR) the number of electricity consumers in Indonesia has increased by an average of 6-7\% annually followed by an increase in the area of its services. An increasingly broad network is directly proportional to the potential for interference with the transmission and distribution system. The 150 KV Rembang substations is part of the Java-Bali Interconnection electrical system in northern Central Java that supplies electricity to the Rembang and surrounding areas. Rembang $150 \mathrm{KV}$ substation on May 24, 2019, RBG 01 feeder experienced a disturbance behind the RB1-32 recloser and it was recorded that in 2019 PMT it had been tripped 4 times. Besides, there has been a change in equipment in the form of transformer II. These problems indicate the potential for interference that is not anticipated by the protection system, namely Over Current Relay and recloser. This study evaluates the setting of an outgoing $20 \mathrm{KV}$ OCR protections and recloser on transformer II RBG 01 feeder Rembang $150 \mathrm{KV}$ substation. The scenarios used are calculations with large variations of short-circuit current based on\% distance, as well as the calculation of OCR and recloser settings with IEC 60255 standards. Setting currents in the protection equipment is regulated based on current conductivity (KHA) and load current on the recloser. The coordination of the protection settings resulting from this resetting will be compared to the conditions on the ground. Existing (field) OCR outgoing feeder RBG 01 condition TMS OCR value =0.228 seconds, Iset $=480 \mathrm{~A}$, and top $=0.3$ seconds. The existing OCR recloser condition TMS OCR value $=0.120$ seconds and Iset $=400$ A. The results of OCR coordinating outgoing feeder RBG 01 obtained TMS OCR value $=0.135$ seconds, Iset $=585 \mathrm{~A}$, and $t$ operation $=0.3$ seconds. OCR recloser resetting conditions obtained TMS OCR value $=0.10$ seconds, Iset $=240 \mathrm{~A}$ and $t$ operation $=0.198$ seconds. The resetting conditions have met the IEC 60255 standard because recloser working time is smaller than outgoing work time..
\end{abstract}

Keywords: Electric power distribution system, short circuit current, OCR, recloser

\begin{abstract}
ABSTRAK
Menurut pengamat energi dari Institute for Essential Services Reform (IESR) jumlah konsumen listrik di Indonesia naik rata-rata pertahun 6-7\% yang diikuti dengan meningkatnya luas daerah pelayanannya. Jaringan yang semakin luas berbanding lurus dengan potensi terjadinya gangguan pada sistem transmisi dan distribusi. Gardu Induk 150 KV Rembang merupakan bagian sistem kelistrikan Interkoneksi Jawa Bali pada Jawa Tengah bagian Utara yang mensupply listrik ke daerah Rembang dan sekitarnya. Gardu Induk 150 KV Rembang tanggal 24 mei 2019 feeder RBG 01 mengalami gangguan di belakang recloser RB1-32 dan tercatat pada 2019 PMT telah trip sebanyak 4 kali. Selain itu, telah terjadi perubahan perangkat berupa pergantian trafo II. Masalah tersebut menunjukkan adanya potensi gangguan yang tidak terantisipasi oleh sistem proteksinya yakni Over Current Relay dan recloser. Kajian ini mengevaluasi setting proteksi OCR outgoing 20 KV dan recloser pada trafo II feeder RBG 01 Gardu Induk 150 KV Rembang. Skenario yang digunakan berupa perhitungan dengan variasi besar arus hubung singkat berdasarkan \% jarak, serta perhitungan setting OCR dan recloser dengan standar IEC 60255. Arus setting pada peralatan proteksinya diatur berdasarkan kuat hantar arus (KHA) dan arus beban pada recloser. Koordinasi setting proteksi hasil resetting ini akan dibandngkan dengan kondisi di lapangan. Kondisi existing (lapangan)OCR outgoing feeder RBG 01 nilai TMS OCR =0,228 detik, Iset $=480$ A, dan t op =0,3 detik. Kondisi existing OCR recloser nilai TMS $O C R=0,120$ detik dan Iset $=400$ A. Hasil Resetting koordinasi OCR outgoing feeder RBG 01 didapatkan nilai TMS OCR = 0,135 detik, Iset $=585$ A, dan t operasi $=0,3$ detik. Kondisi resetting OCR recloser didapatkan nilai TMS OCR =0,10 detik, Iset $=240$ A dan t operasi $=0,198$ detik. Kondisi resetting telah memenuhi standar IEC 60255 karena waktu kerja recloser lebih kecil dari waktu kerja outgoing.
\end{abstract}

Kata Kunci : sistem distribusi tenaga listrik, arus hubung singkat, OCR, recloser

\section{Pendahuluan}

$\mathrm{S}$ istem distribusi adalah suatu komponen dari sistem tenaga listrik yang berfungsi untuk mengalirkan tenaga listrik berdaya listrik besar hingga ke konsumen. Perkembangan jaringan pada sistem distribusi sangat diperlukan mengingat setiap tahunnya pengguna listrik semakin bertambah sehingga menyebabkan suatu sistem distribusi tidak bebas dari 
berbagai gangguan. Gangguan yang sering terjadi di sistem distribusi baik gangguan hubung singkat 2 fasa, 3 fasa dapat menyebabkan kenaikan arus lebih yang dapat menganggu proses penyaluran tenaga listrik dan menyebabkan pemadaman. Salah satu cara menanggani gangguan hubung singkat ialah membatasi daerah gangguan dan memperkecil waktu terjadinya gangguan hubung singkat, hal ini dapat diperoleh dengan sistem proteksi yang andal. Peralatan proteksi pada sistem distribusi diantaranya ialah relai arus lebih dan recloser. Relai arus lebih ialah jenis relai yang beroperasi dengan mendeteksi adanya arus lebih yang dirasakan relai dan selanjutnya relai akan memerintahkan PMT untuk trip[1]. Sistem proteksi agar dapat bekerja dengan baik dalam mengamankan sistem dari gangguan maka dibutuhkan koordinasi peralatan proteksi yang terpasang baik pada incoming dan outgoing feeder maupun pada pengaman yang terpasang pada jaringan $20 \mathrm{KV}$ (recloser) [2]. Koordinasi peralatan proteksi dapat diperoleh dengan mendapatkan nilai setting yang lebih akurat agar sistem proteksi dapat beroperasi dengan baik.

Gardu Induk $150 \mathrm{KV}$ Rembang tidak lepas dari gangguan, salah satunya adalah kejadian pada tanggal 24 mei 2019 di feeder RBG 01 mengalami gangguan dibelakang recloser RB1-32 dengan sistem yang tidak bekerja dengan baik dan pada tahun 2019 telah terjadi sebanyak 4 kali tripnya PMT sisi outgoing feeder RBG 01 . Gardu Induk $150 \mathrm{KV}$ Rembang mengalami pergantian trafo II dari yang semula berkapasitas daya 30 MVA diganti menjadi $60 \mathrm{MVA}$, hal ini mempengaruhi setting antar peralatan proteksi. Namun, kondisi koordinasi setting proteksi sisi incoming dan outgoing telah berjalan dengan baik, namun koordinasi proteksi sisi outgoing dengan pengaman di saluran yakni recloser belum berjalan dengan baik karena belum diperbaiki sehingga masih berdasar pada kapasitas daya trafo II 30 MVA.

Berdasarkan latar belakang permasalahan tersebut, maka penelitian ini akan membahas koordinasi setting proteksi relai arus lebih sisi outgoing $20 \mathrm{KV}$ dan recloser pada feeder RBG 01 Trafo II 60 MVA. Analisa pada penelitian ini akan berdasarkan pada pada metode penelitian yakni studi pustaka dan studi lapangan dengan dilakukannya wawancara oleh pihak terkait.

Perumusan masalah pada penelitian ini adalah : Bagaimana membuat analisis dari kondisi koordinasi proteksi relai arus lebih (OCR) outgoing $20 \mathrm{KV}$ dan recloser pada Trafo II 60 MVA feeder RBG 01 di Gardu Induk $150 \mathrm{KV}$ Rembang yang belum bekerja dengan efektif dan selektif, Bagaimana cara untuk membuat pengaturan ulang setting relai arus lebih (OCR) outgoing $20 \mathrm{KV}$ dan recloser, Bagaimana analisis dari kinerja relai arus lebih (OCR) outgoing $20 \mathrm{KV}$ dan recloser pada saat terjadi gangguan hubung singkat didekatnya.
Tujuan dari penelitian ini adalah : Membuat analisis kinerja yang dapat meningkatkan kinerja dari koordinasi proteksi relai arus lebih (OCR) outgoing $20 \mathrm{KV}$ dan recloser pada Trafo II 60 MVA feeder RBG 02 agar dapat selektif dalam memilih daerah yang harus diisolir saat terjadi gangguan, Melakukan analisis perhitungan ulang untuk kinerja setting relai arus lebih (OCR) outgoing $20 \mathrm{KV}$ dan recloser dengan berdasarkan kapasitas daya trafo II yang dipakai yakni 60 MVA, Mengetahui status keandalan dan kepekaan relai arus lebih saat terjaadi gangguan didekatnya.

\section{TINJAUAN DAN LANDASAN TEORI}

Penelitian yang dilakukan oleh Alfian Syafi'i (2016), membahas tentang "Analisa Koordinasi Recloser dan OCR (Over Current Relay) untuk Gangguan Hubung Singkat Pada Penyulang 3 Distribusi 20 KV GI JAJAR". Waktu kerja recloser harus lebih cepat jika dibandingkan dengan waktu kerja dari OCR pada outgoing dan incoming karena recloser merupakan cadangan proteksi artinya saat terjadi gangguan dihilir agar dapat dilokalisir pemadaman di zona proteksi recloseratau dapat dikatakan pemadaman hanya terjadi di area gangguan [3].

Penelitian yang dilakukan oleh Adytya Ramadani (2018), membahas tentang "Analisa Koordinasi Recloser Dan OCR (Over Current Relay) Untuk Hubung Singkat Pada Penyulang 9 Distribusi 20 KV GI BAWEN". Besarnya nilai impedansi dapat mempengaruhi besarnya nilai arus gangguan, jika nilai impedansi kecil maka nilai arus gangguan akan semakin besar begitu juga sebaliknya artinya waktu kerja dari OCR dan recloser dipengaruhi oleh faktor impedansi [4].

\section{Gangguan Hubung Singkat}

Gangguan listrik ialah gangguan yang disebabkan hubungan langsung antar fasa (fasa R-S, fasa R$\mathrm{T}$, fasa T-S, fasa R-S-T yang terhubung langsung) atau fasa tanah yang dapat terjadi pada sistem tenaga listrik jaringan, gardu induk atau pusat listrik. Gangguan hubung singkat merupakan gangguan yang terjadi karena adanya masalah atau kesalah dari bagian yang bertegangan. Besarnya arus gangguan dipengaruhi oleh nilai impedansi sumber dan impedansi jaringan yang dilewati oleh gangguan hubung singkat. Gangguan hubung singkat harus segera diatasi karena jika dibiarkan dapat menyebabkan berkurangnya kestabilan sistem daya dan rusaknya peralatan didekat titik gangguan yang disebabkan karena arus tak seimbang[5]. Rumus dasar arus ganggun hubung singkat adalah :

$$
I_{h s}=\frac{V}{Z}
$$

\section{Keterangan :}

Ihs = Arus yang mengalir di hambatan Z (Ampere)

$\mathrm{V}=$ Tegangan pada sumber (Volt) 
$\mathrm{Z}$ = Impedansi jaringan, nilai ekuivalen dari seluruh impedansi dalam jaringan dari sumber tegangan sampai titik gangguan.

Beberapa macam gangguan hubung singkat yang terjadi pada jaringan distribusi adalah sebagai berikut:

1. Gangguan Hubung Singkat 2 Fasa

Gangguan hubung singkat 2 fasa disebabkan karena antara fasa B-C dan terhubungnya fasa B-C dikarenakan terdapat adanya tahanan Zf. Pada gangguan hubung singkat 2 fasa, arus saluran tidak mengandung komponen nol karena tidak ada gangguan yang tersambungke tanah. Rumus untuk menghitung arus hubung singkat 2 fasa adalah [2] :

$$
I_{f 2}=\frac{V_{f}}{Z_{1}+Z_{2}}
$$

Keterangan :

$\mathrm{I}_{\mathrm{f} 2} \quad$ = Arus gangguan hubung singkat 2 fasa (Ampere)

$\mathrm{Z}_{1} \quad=$ Impedansi urutan positif dilihat dari titik gangguan (ohm)

Z2 = Impedansi urutan negatif dilihat dari titik gangguan $(\mathrm{ohm})$

Vf $\quad=$ Tegangan fasa ke fasa (Volt)

2. Gangguan Hubung Singkat 3 Fasa

Gangguan hubung singkat 3 fasa tergolong gangguan simetris yang merupakan gangguan dengan arus seimbang, hal ini karena pada gangguan 3 fasa nilai arus dan tegangan pada tiap fasanya tetap seimbang setelah terjadinya gangguan. Gangguan ini dapat terjadi karena terhubungnya ketiga fasanya oleh pohon, kawat atau benang layanglayang. Rumus arus hubung singkat 3 fasa adalah[2]

$$
\mathrm{I}_{\mathrm{A} 3}=\frac{\mathrm{V}_{\mathrm{f}}}{\mathrm{Z}_{1}}
$$

Keterangan :

$\mathrm{I}_{\mathrm{f} 2}=$ Arus gangguan hubung singkat 3 fasa (Ampere)

$\mathrm{Z}_{1} \quad=$ Impedansi urutan positif dilihat dari titik gangguan (ohm)

Vf = Tegangan dititik gangguan sebelum terjadi gangguan (Volt)

\section{Relai Arus Lebih (Over Current Relay)}

Relai arus lebih (over current relay) merupakan relai yang beroperasi untuk mendeteksi adanya kenaikan arus yang naik yang melebihi/melewati nilai yang sudah ditentukan yang dapat diakibatkan karena gangguan hubung singkat dan overload. Relai arus lebih (over current relay) juga berfungsi sebagai relai yang mengamankan transformator dari besarnya arus yang melebihi batas arus yang ditentukan untuk melewati transformator. Jika pada sistem terjadi gangguan antar fasa atau gangguan tiga fasa dengan arus yang melebihi sudah di setting maka relai arus lebih akan memberikan perintah kepada PMT untuk membuka atau trip [2].

Arus setting merupakan besarnya arus yang tidak boleh dilewati agar relai masih tetap bisa bekerja. Karakteristik relai arus lebih (over current relay) ditentuakn atas dasar arus setting dan waktu yang diperlukan untuk kerja relai dengan tujuan untuk mencapai suatu tingkat sensitivitas yang diinginkan.

Karakteristik dari relai arus lebih (over current relay) di Gardu Induk 150 KV Rembang adalah Invers Time Relay ( Relai Arus Lebih Waktu Terbalik). Relai arus lebih waktu terbalik merupakan karakteristik relai dengan grafik antara arus dan dan waktu yang terbalik, artinya semakin besar arus maka akan semakin kecil waktu yang dibutuhkan untuk membuka atau mentripkan pemutus (PMT).

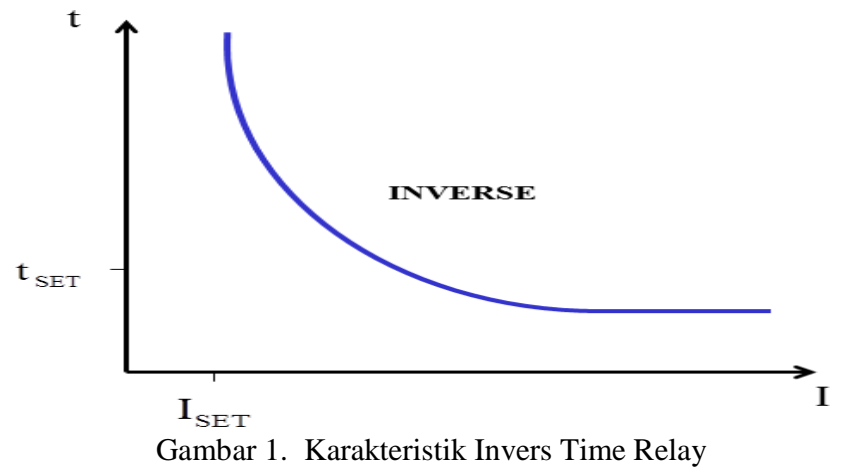

Menurut standar IEC 60255 dalam dilakukan dengan persamaan berdasarkan karakteristik relai yang digunakan. Gardu Induk $150 \mathrm{KV}$ Rembang menggunakan relai dengan Standar Invers [6].

Standar Invers

$$
\mathrm{t}=\frac{0,14 \mathrm{xTMS}}{\left[\frac{\mathrm{Ihs}}{\mathrm{Iset}}\right]^{0,02}-1}
$$

Keterangan :

$\mathrm{t}=$ Waktu kerja relai (detik/ $\mathrm{s})$

Ihs = Arus hubung singkat (Ampere)

Iset $=$ Arus setelan relai (Ampere)

TMS = Time Multiple Setting adalah karakteristik relai yang diinginkan sesuai dengan hasil perhitungan.

\section{Recloser}

Recloser atau pemutus balik otomatis (PBO) pada prinsipnya merupakan pemutus tenaga (circuit breaker) yang didalamnya dilengkapi dengan peralatan control (control device). Recloser atau pemutus balik otomatis (PBO) adalah sebuah pengaman yang beroperasi dengan mendeteksi adanya gangguan yang mengakibatkan adanya arus lebih, salah satunya diakibatkan karena hubung singkat antara fasa-fasa atau fasa dengan tanah. Recloser akan memutus arus dan menutup kembali secara otomatis dengan waktu tunda yang diatur sesuai setting interval recloser. Menentukan setting OCR di 
recloser menggunakan rumus yang sama denngan rumus yang digunakan untuk setting OCR di outgoing yang membedakan adalah penentuan nilai $t$ yang lebih kecil dari outgoing[7].

Recloser sering dipasang pada SUTM (Saluran Udara Tegangan Menengah) yang sering terjadi gangguan yang bersifat permanen. Fungsi dan kegunaan dari recloser adalah sebagai berikut [2]:

1. Mengamankan peralatan listrik/ jaringan SUTM jika terjadi gangguan hubung singkat temporer/ sementara ataupun permanen

2. Menormalkan SUTM atau membatasi daerah pemadaman tetap yang disebabkan gangguan temporer

3. Membatasi / melokalisir daerah yang terganggu sebagai pengaman seksi dalam SUTM

4. Memisahkan jaringan yang terganggu secara cepat sehingga bisa membatasi area yang terdampak saat gangguan sementara (temporer)

\section{Koordinasi Relai PMT Outgoing dan Recloser}

Pada prinsipnya koordinasi antara relai PMT pada sisi outgoing dan recloser adalah relai PMT outgoing (kurva A) sebagai pengaman cadangan dari recloser (kurva B). Kurva setting PMT harus berada di atas recloser sehingga waktu kerja dari recloser harus lebih kecil atau lebih cepat dari setting waktu dari relai PMT di sisi outgoing[8]

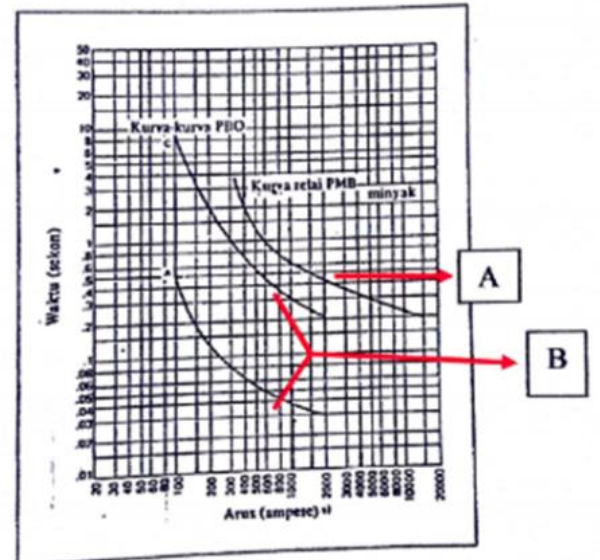

Gambar 2. Koordinasi PMT Outgoing dan Recloser

\section{METODE PENELITIAN}

Pada penelitian ini akan diawali dengan menentukan lokasi penelitian untuk kemudian akan dilakukan pengumpulan data-data penelitian. Pada penelitian ini penulis menentukan lokasi di Gardu Induk $150 \mathrm{KV}$ Rembang pada Trafo II 60 MVA feeder RBG 01 dikarenakan terdapat masalah koordinasi OCR sisi outgoing dan recloser yang tidak bekerja sebagaimana mestinya. Panjang feeder RBG 01 sebesar 5,34 km.

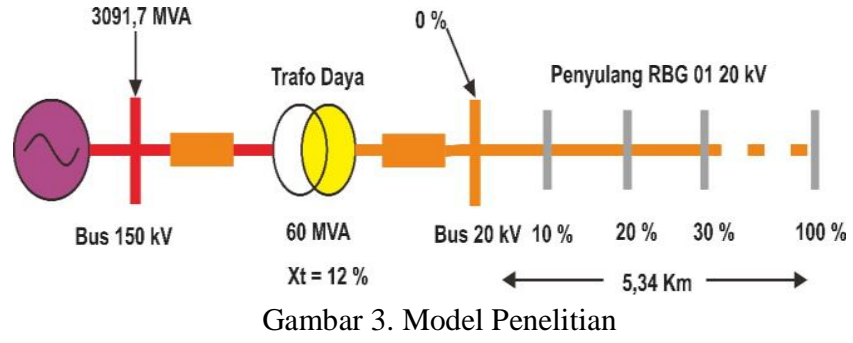

Berikut ini merupakan diagram blok untuk urutan pada relay proteksi sebagai berikut [9] :

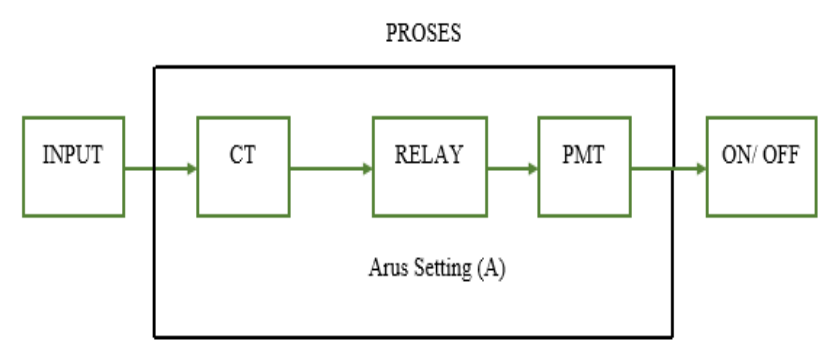

Gambar 4. Arsitektur Model Penelitian

Pada penelitian ini menggunakan metode penelitian berupa metode waterfall, yang artinya setiap tahapan dilakukan secara berurutan dan berkelanjutan. Penelitian ini diangkat berdasarkan studi kasus di Gardu Induk $150 \mathrm{KV}$ Rembang, sehingga data yang digunakan merupakan data asusmi.

Data-data pada penelitian ini dibagi menjadi 2 yaitu data primer dan data sekunder. Data primer berupa sigle line diagram, spesifikasi trafo II Gardu Induk $150 \mathrm{KV}$ Rembang, data teknis penghantar berupa jenis dan luas penghantar, panjang saluran, arus beban recloser dan data setting OCR outgoing $20 \mathrm{KV}$ dan recloser diperoleh dengan metode wawancara ke bagian proteksi di PT. PLN (Persero) APD Jateng \& DIY serta bagian jaringan di UP3 Kudus. Data sekunder yang didapat dari beberapa buku dan jurnal-jurnal yang dilakukan peneliti terdahulu dengan topik yang berhubungan dengan koordinasi OCR outgoing dan recloser sebagai acuan dalam menyusun penelitian ini.

Data yang didapatkan dari PT. PLN APD Jateng \& DIY Semarang dan UP3 Kudus kemudian akan dilakukan pengolahan dengan menggunakan skenario gangguan berdasarkan variabel bebas dan terikat yang digunakan sehingga dapat di analisa bagaimana kondisi koordinasi OCR (Over Current Relay) pada outgoing dan recloser agar dapat memberikan solusi terkait kondisi koordinasi OCR (outgoing, recloser) pada feeder RBG 01 GI Rembang. 
Skenario gangguan pada penelitian ini menggunakan variabel bebas berupa presentase arus gangguan hubung singkat dengan berdasarkan jarak. Sedangkan variabel terikatnya berupa nilai arus setting, TMS dan waktu (t) operasi dari relai arus lebih (OCR).

Diagram flow chart penelitian

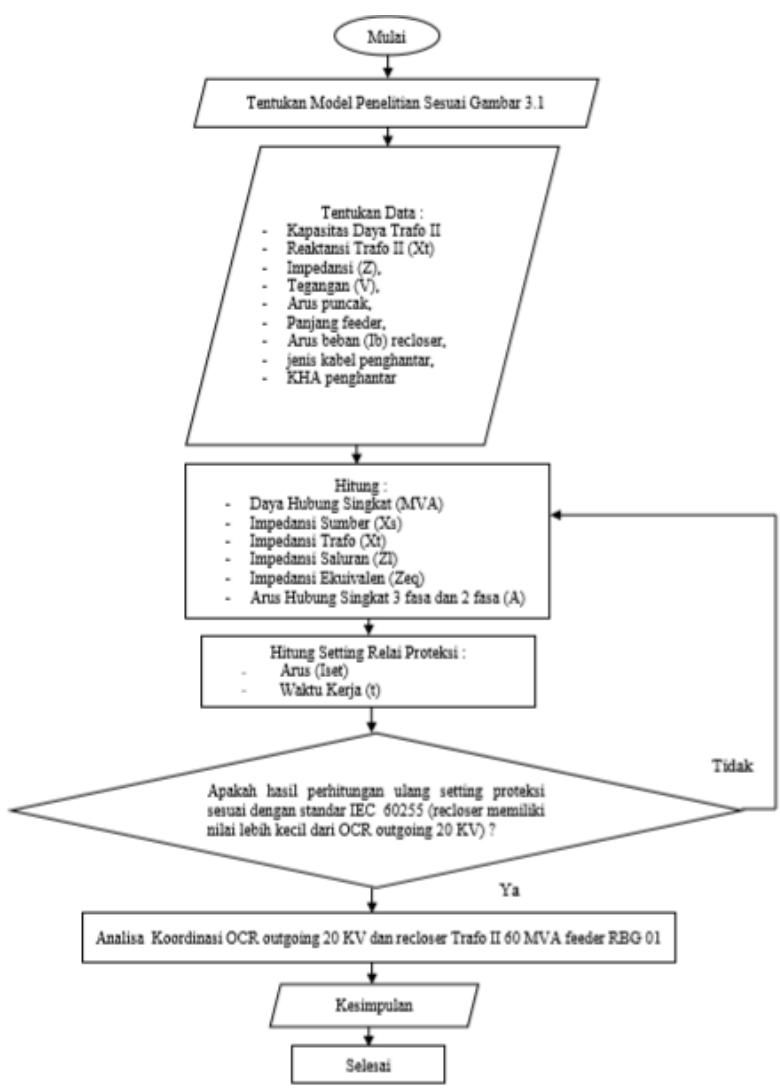

Gambar 5. Diagram Alir Penelitian

\section{HASIL DAN PEMBAHASAN}

Untuk menentukan nilai resetting proteksi OCR pada sisi outgoing dan recloser pada trafo II feeder RBG 01 maka harus melakukan perhitungan arus gangguan hubung singkat dengan menggunakan persamaan 2 dan 3 . Arus gangguan hubung singkat ( 2 dan 3 fasa) ini akan dilakukan perhitungan berdasarkan besarnya presentase jarak dari 0\%-100\% dengan data kapasitas daya trafo II yang terpasang.

\section{A. Arus Gangguan Hubung Singkat Resetting}

Untuk menentukan arus gangguan hubung singkat, terlebih dahulu harus menghitung beberapa nilai-nilai dibawah ini :

\section{- Impedansi Sumber(Xs)}

Nilai impedansi sumber Xs diperoleh dari nilai arus puncak yang mengalir dari sistem interkoneksi ke gardu induk. Arus puncak di GI 150 KV Rembang sebesar 11,9 kA sehingga besarnya nilai daya hubung singkat adalah

$$
\begin{aligned}
\text { MVAsc } & =\sqrt{3} \times \mathrm{V} \times \mathrm{I} \\
& =\sqrt{3} \times 150 \times 11,9 \\
& =3091,7 \mathrm{MVA} \\
\mathrm{Xsc}_{(\operatorname{sisi} 150 \mathrm{KV})} & =\frac{\mathrm{KV}^{2}}{\mathrm{MVAsc}}=\frac{150^{2}}{3091,7}=\frac{22500}{3091,7} \\
& =7,27 \mathrm{ohm}
\end{aligned}
$$

Dikarenakan arus gangguan hubung singkat yang dicari adalah gangguan hubung singkat pada sisi $20 \mathrm{KV}$ maka nilai impedansi sumber sisi $150 \mathrm{KV}$ harus dikonversikan ke sisi $20 \mathrm{KV}$.

$$
\begin{aligned}
\mathrm{Xsc}_{(\operatorname{sisi} 20 \mathrm{KV})} & =\frac{\mathrm{KV} 2^{2}}{\mathrm{KV}^{2}} \cdot \mathrm{Xsc}_{(\text {sisi 150KV })} \\
= & \frac{20^{2}}{150^{2}} \times 7,27 \\
& =\frac{400}{22500}=0,129 \mathrm{ohm}
\end{aligned}
$$

\section{- Impedansi Transformator (Xt)}

Nilai reaktansi trafo II GI $150 \mathrm{KV}$ Rembang sebesar $12 \%$ dengan kapasitas daya trafo II sebesar 60 MVA. Untuk dapat mengetahui nilai reaktansi urutan positif, negatif dalam ohm terlebih dahulu menghitung besarnya nilai Xt pada saat $100 \%$.

$$
\begin{aligned}
\mathrm{Xt}_{(\text {pada 100\%) }}= & \frac{\mathrm{KV}^{2}}{\mathrm{MVA}}=\frac{20^{2}}{60}=\frac{400}{60} \\
& =6,6 \mathrm{ohm}
\end{aligned}
$$

Nilai reaktansi trafo urutan positif dan negatif $\mathrm{Xt}_{1}=\mathrm{Xt}_{2}$ adalah sebesar $=$

$$
\begin{aligned}
& \mathrm{Xt}_{1}=\mathrm{Xt}_{2} \\
& =\% \text { yang diketahui } \times \mathrm{Xt}_{(\text {pada } 100 \%)} \\
& \quad=12 \% \times 6,6 \\
& =0,12 \times 6,6 \\
& =0,792 \mathrm{ohm}
\end{aligned}
$$

\section{- Impedansi Saluran Penyulang/ Feeder}

Feeder RBG 01 menggunakan jenis penghantar AAAC $240 \mathrm{~mm} 2$ dengan panjang feeder RBG 01 sebesar $5,34 \mathrm{~km}$.

$$
\begin{aligned}
& \mathrm{Z}=(\mathrm{R}+\mathrm{jX}) \mathrm{ohm} / \mathrm{km} \\
& \mathrm{Z}_{1}=\mathrm{Z}_{2}=(0,1344+ \\
& \mathrm{j} 0,3158) \text { ohm } \times \text { panjang feeder } \\
& \mathrm{Z}_{1}=\mathrm{Z}_{2}=(0,1344+\mathrm{j} 0,3158) \times 5,34 \\
& \mathrm{Z}_{1}=\mathrm{Z}_{2}=0,7176+\mathrm{j} 1,6863 \mathrm{ohm}
\end{aligned}
$$

Selanjutnya akan menentukan nilai impedansi urutan positif, negatif pada penyulang/ feeder RBG 01 menggunakan cara seperti diatas dengan presentase jarak 0\% hingga $100 \%$.

\section{- Impedansi Ekuvalen}

Nilai impedansi ekuvalen diperoleh dengan menjumlahkan nilai impedansi sumber, impedansi trafo dan 
impedansi saluran dengan presentase jarak $0 \%$ hingga $100 \%$.

$$
\begin{aligned}
& \mathrm{Zeq}=\mathrm{Z}_{1 \mathrm{eq}}=\mathrm{Z}_{2 \mathrm{eq}} \\
& =\mathrm{Xs}_{(\text {sisi 20KV) }}+\mathrm{X}_{\mathrm{t}}+\text { Zfeeder }_{(\mathrm{jarak} 100 \%} \\
& =\mathrm{j} 0,129+\mathrm{j} 0,792+0,7176+\mathrm{j} 1,6863 \\
& =\mathrm{j} 0,921+0,7176+\mathrm{j} 1,6863 \\
& =0,7176+\mathrm{j} 2,6073 \mathrm{ohm}
\end{aligned}
$$

Nilai impedansi Z dipengaruhi oleh besarnya nilai jarak karena semakin besar presentase jarak maka nilai impedansi akan semakin besar pula.

Tabel 1. Impedansi penyulang

\begin{tabular}{c|c|c|c}
\hline \multirow{2}{*}{ \% Jarak } & \multirow{2}{*}{$\begin{array}{c}\text { Jarak } \\
\end{array}$} & \multicolumn{2}{|c}{$\mathrm{Z} 1=\mathrm{Z} 2(\mathrm{ohm})$} \\
\cline { 3 - 4 } & 0 & $\mathrm{R}(\mathrm{ohm})$ & $\mathrm{jX}(\mathrm{ohm})$ \\
\hline 0 & 0,534 & 0,07176 & 0 \\
10 & 1,068 & 0,14352 & 0,33726 \\
20 & 1,602 & 0,21528 & 0,50589 \\
30 & 2,136 & 0,28704 & 0,67452 \\
40 & 2,67 & 0,3588 & 0,84315 \\
50 & 3,201 & 0,43056 & 1,01178 \\
60 & 3,738 & 0,50232 & 1,18041 \\
70 & 4,272 & 0,57408 & 1,34904 \\
80 & 4,806 & 0,64584 & 1,51767 \\
90 & 5,34 & 0,7176 & 1,6863 \\
100 & 1,99 & 0,2683 & 0,6306 \\
\hline
\end{tabular}

Tabel 2. Impedansi Ekivalen

\begin{tabular}{c|c|c|c}
\multirow{4}{*}{ \% Jarak } & \multirow{2}{*}{$\begin{array}{c}\text { Jarak } \\
\end{array}$} & \multicolumn{2}{|c}{$\mathrm{Z} 1=\mathrm{Z} 2(\mathrm{ohm})$} \\
\cline { 3 - 4 } & 0 & $\mathrm{R}(\mathrm{ohm})$ & $\mathrm{jX}(\mathrm{ohm})$ \\
\hline 0 & 0,534 & 0,07176 & 0,921 \\
10 & 1,068 & 0,14352 & 1,2596 \\
20 & 1,602 & 0,21528 & 1,4268 \\
30 & 2,136 & 0,28704 & 1,5955 \\
40 & 2,67 & 0,3588 & 1,7641 \\
50 & 3,201 & 0,43056 & 1,9327 \\
60 & 3,738 & 0,50232 & 2,1014 \\
70 & 4,272 & 0,57408 & 2,2700 \\
80 & 4,806 & 0,64584 & 2,4386 \\
90 & 5,34 & 0,7176 & 2,6073 \\
100 & 1,99 & 0,2683 & 1,5516 \\
\hline
\end{tabular}

Nilai impedansi ekuvalen pada tabel 2 akan digunakan untuk mencari besarnya nilai arus gangguan hubung singkat 2 fasa dan 3 fasa pada trafo II feeder RBG 01 dengan presentase jarak 0\%-100\%. Berikut ini adalah persamaan untuk menghitung arus gangguan hubung singkat 2 fasa dan 3 fasa :

$$
\begin{aligned}
& I_{2 \text { fasa }}=\frac{V p h-p h}{2 \times Z_{1 e q}}=\frac{20000}{2 \times Z_{1 e q}} \\
& I_{3 \text { fasa }}=\frac{\frac{20000}{\sqrt{3}}}{Z_{1 \text { eq }}}=\frac{11547}{Z_{1 \text { eq }}}
\end{aligned}
$$

Tabel 3. Arus Hubung Singkat Resetting

\begin{tabular}{cccc}
\hline \multicolumn{4}{c}{ Arus Gangguan Hubung Singkat (A) } \\
\hline$\%$ Jarak & Jarak $(\mathrm{km})$ & 2 Fasa & 3 Fasa \\
\hline 0 & 0 & 10857,76 & 12537,46 \\
10 & 0,534 & 9157,59 & 10574,24 \\
20 & 1,068 & 7896,28 & 9117,84 \\
30 & 1,602 & 6929,82 & 8001,86 \\
40 & 2,136 & 6168,52 & 7366,13 \\
50 & 2,67 & 5554,73 & 7122,76 \\
60 & 3,201 & 5050,11 & 6414,05 \\
70 & 3,738 & 4628,32 & 5344,32 \\
80 & 4,272 & 4270,76 & 4931,44 \\
90 & 4,806 & 3963,94 & 4577,16 \\
100 & 5,34 & 3697,88 & 4269,95 \\
REC RB1-32 & 1,99 & 6350,35 & 7332,75 \\
\hline
\end{tabular}

Tabel 4. Arus Hubung Singkat Existing

\begin{tabular}{ccccc}
\hline \multicolumn{4}{c}{ Arus Gangguan Hubung Singkat (A) } \\
\hline \% Jarak & Jarak $(\mathrm{km})$ & 2 Fasa & 3 Fasa \\
\hline 0 & 0 & 6854,01 & 7914,32 \\
10 & 0,534 & 6137,94 & 7087,48 \\
20 & 1,068 & 5549,44 & 6407,94 \\
30 & 1,602 & 5059,07 & 5841,71 \\
40 & 2,136 & 4645,24 & 5363,86 \\
50 & 2,67 & 4291,95 & 4955,92 \\
60 & 3,201 & 3987,22 & 4604,04 \\
70 & 3,738 & 3721,92 & 4297,70 \\
80 & 4,272 & 3489,03 & 4028,79 \\
90 & 4,806 & 3283,07 & 3790,96 \\
100 & 5,34 & 3099,70 & 3579,22 \\
\hline
\end{tabular}

\section{B.Setting Proteksi OCR Outgoing dan Recloser \\ -Setting Proteksi OCR sisi Outgoing}

Menentukan nilai setting waktu kerja dari relai arus lebih (OCR) sisi outgoing trafo II GI Rembang adalah dengan mencari nilai TMS dengan menggunakan pers 4. Menurut standar IEC 60255 nilai waktu kerja dari relai sisi outgoing bernilai $0,3-0,5$ detik. Besarnya nilai arus setting relai arus lebih/ OCR outgoing tergantung pada besarnya nilai KHA maksimum pada penghantar yang digunakan. Sesuai dengan aturan yang ada pada SPLN 64 : 1985 yang menyatakan bahwa besarnya nilai KHA pada penghantar AAAC $240 \mathrm{~mm}^{2}$ adalah sebesar 585 Ampere. Besarnya arus gangguan yang digunakan dalam menentukan nilai TMS pada OCR outgoing trafo II adalah arus gangguan hubung singkat tiga fasa pada titik jarak $0 \%$ dari panjang feeder RBG 01.

Besarnya arus setting (Iset) OCR

$$
\text { Iset }=585 \text { Ampere }
$$

Besarnya nilai TMSOCR

$$
\begin{aligned}
\mathrm{TMS}_{\mathrm{OCR}} & =\frac{\left[\frac{\text { Ihs } 3 \emptyset}{\text { Iset }}\right]^{0,02}-1}{0,14} \times \mathrm{t} \\
\mathrm{TMS}_{\mathrm{OCR}} & =\frac{\left[\frac{12537,46}{585}\right]^{0,02}-1}{0,14} \times 0,3
\end{aligned}
$$


$\mathrm{TMS}_{\mathrm{OCR}}=0,135$ detik

Tabel 5. Perbandingan Waktu Kerja OCR sisi Outgoing

\begin{tabular}{l|l|l|l}
\hline Feeder & Setting & Existing & $\begin{array}{l}\text { Hasil Perhi- } \\
\text { tungan/ Re- } \\
\text { Setting }\end{array}$ \\
\cline { 3 - 4 } & & & OCR \\
\cline { 3 - 4 } & & OCR & 0,135 \\
\hline RBG 01 & TMS & 0,228 & 585 \\
& Iset (A) & 480 &
\end{tabular}

Berdasarkan Tabel 5 menunjukkan bahwa nilai arus setting (Iset) dan TMS pada relai sisi outgoing memiliki perbedaan nilai. Pada hasil perhitungan/ resetting untuk feeder RBG 01, nilai arus setting didapatkan dari nilai kuat hantar arus (KHA) maksimum penghantar, penghantar yang digunakan adalah AAAC $240 \mathrm{~mm}^{2}$. Nilai arus setting OCR dari hasil perhitungan/ resetting adalah $585 \mathrm{~A}$ sedangkan nilai arus setting existing OCR

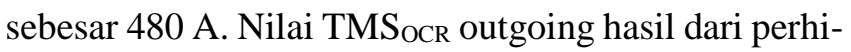
tungan/ resetting didapatkan sebesar 0,135 detik sedangkan nilai $\mathrm{TMS}_{\mathrm{OCR}}$ dari existing sebesar 0,228 detik.

\section{-Setting Proteksi OCR pada Recloser}

Waktu kerja pada sisi recloser sebesar 0,2 detik karena menurut standard IEC 60255 waktu kerja pada sisi recloser harus lebih kecil atau lebih cepat dari waktu kerja sisi outgoing. Besarnya nilai arus setting ditentukan oleh arus beban yang mengalir pada recloser yaitu 200 Ampere (sumber PT.PLN APD Jateng \& DIY) dan besarnya nilai arus gangguan hubung singkat 3 fasa pada recloser adalah 7366,13 A. Recloser pada feeder RBG 01 ini berada pada jarak 1,99 km. Arus setting (Iset) OCR recloser dapat dilakukan perhitungan dengan mengalikan konstanta $(\mathrm{K})$ dengan arus beban yang mengalir. Nilai konstanta (K) bernilai 1,05 - 1,2. Besarnya arus setting (Iset) OCR Recloser

Iset $=\mathrm{Kx}$ arus beban yang mengalir

Iset $=1,2 \times 200$

Iset $=240 \mathrm{~A}$

Besarnya nilai TMS Recloser

$$
\begin{aligned}
\mathrm{TMS}_{\mathrm{OCR}} & =\frac{\left[\frac{\text { Ihs } 3 \emptyset}{\text { Iset }}\right]^{0,02}-1}{0,14} \times \mathrm{t} \\
\mathrm{TMS}_{\mathrm{OCR}} & =\frac{\left[\frac{7332,13}{240}\right]^{0,02}-1}{0,14} \times 0,2 \\
\mathrm{TMS}_{\mathrm{OCR}} & =0,10 \text { detik }
\end{aligned}
$$

Tabel 6. Perbandingan Waktu Kerja Recloser

\begin{tabular}{l|l|l|l}
\hline Feeder & Setting & Existing & $\begin{array}{l}\text { Hasil Perhi- } \\
\text { tungan/ Re- } \\
\text { Setting }\end{array}$ \\
\cline { 3 - 4 } & & & Recloser \\
\cline { 3 - 4 } RBG 01 & TMS & 0,12 & 0,10 \\
& Iset (A) & 400 & 240 \\
\hline
\end{tabular}

Perbandingan nilai setting pada recloser (pemutus balik otomatis) di feeder RBG 01 antara nilai existing dan hasil perhitungan /resetting memiliki nilai yang sedikit berbeda. Nilai arus existing (kondisi di lapangan) pada recloser sebesar $400 \mathrm{~A}$ sedangan nilai arus setting pada recloser hasil perhitungan sebesar $240 \mathrm{~A}$ hal ini karena nila arus beban yang mengalir di recloser hanya sebesar 200 A. Nilai existing TMS recloser adalah 0,12 detik dan nilai TMS recloser hasil dari perhitungan/ resetting juga bernilai 0,12 detik hal ini dikarenakan arus setting nya yang bernilai kecil dan arus hubung singkat 3 fasa di recloser bernilai 7332,75 A.

\section{Pemeriksaan Waktu Kerja Relai}

Pemerikasaan waktu kerja dari relai OCR outgoing dilakukan untuk mengetahui waktu kerja relai terhadap adanya arus gangguan hubung singkat 3 fasa dan 2 fasa dengan presentase gangguan yang terjadi pada titik jarak 0\% hingga 100\% dari panjang feeder RBG 01.

\section{-Waktu Kerja OCR Outgoing Saat Gangguan 3}

\section{Fasa dan 2 Fasa}

Pemeriksaan waktu kerja OCR outgoing dengan nilai arus gangguan hubung singkat 3 fasa dan 2 fasa akan dilakukan perhitungan dengan persamaan 4 untuk mencari nilai waktu kerja OCR outgoing dengan presentase arus gangguan hubung singkat pada saat gangguan terjadi pada titik jarak $0 \%$ dan $100 \%$.

Gangguan hubung singkat 3 fasa titik jarak $0 \%$

$$
\begin{aligned}
\mathrm{t} & =\frac{0,14 \times \mathrm{TMS}}{\left[\frac{\mathrm{hs} 3 \emptyset}{\text { Iset }}\right]^{0,02}-1} \\
& =\frac{0,14 \times 0,135}{\left[\frac{12537,46}{585}\right]^{0,02}-1} \\
& =0,3 \mathrm{~s}
\end{aligned}
$$

Gangguan hubung singkat 3 fasa titik jarak $10 \%$

$$
\mathrm{t}=\frac{0,14 \times \mathrm{TMS}}{\left[\frac{\mathrm{Ihs} 3 \emptyset}{\text { Iset }}\right]^{0,02}-1}=\frac{0,14 \times 0,135}{\left[\frac{10574,27}{585}\right]^{0,02}-1}
$$


Tabel 7. Waktu Kerja OCR Outgoing Pada Gangguan 3 dan 2 fasa

\begin{tabular}{ccc}
\hline \% Titik & \multicolumn{2}{|c}{ Pemeriksaan Waktu Kerja OCR outgoing (t) } \\
\cline { 2 - 3 } Jarak & Gangguan 3 Fasa & Gangguan 2 Fasa \\
\hline 0 & 0,3 & 0,315 \\
10 & 0,318 & 0,335 \\
20 & 0,336 & 0,355 \\
30 & 0,353 & 0,374 \\
40 & 0,370 & 0,393 \\
50 & 0,387 & 0,412 \\
60 & 0,403 & 0,430 \\
70 & 0,419 & 0,449 \\
80 & 0,435 & 0,468 \\
90 & 0,452 & 0,486 \\
100 & 0,468 & 0,505 \\
\hline
\end{tabular}

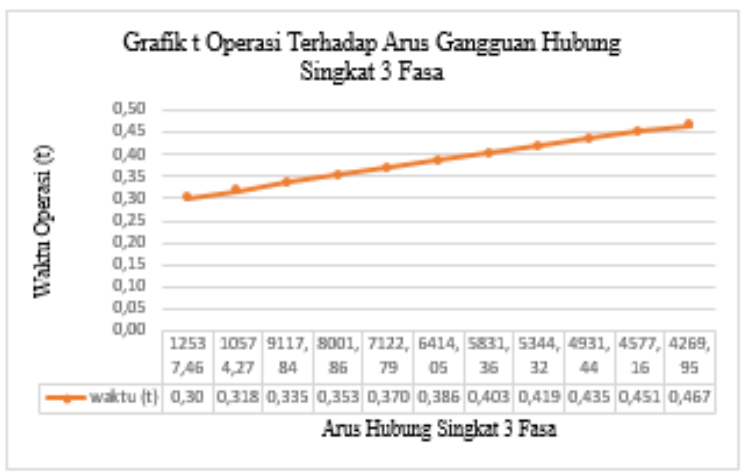

Gambar 3. Gambar grafik t Operasi terhadap Ihs 3 Fasa

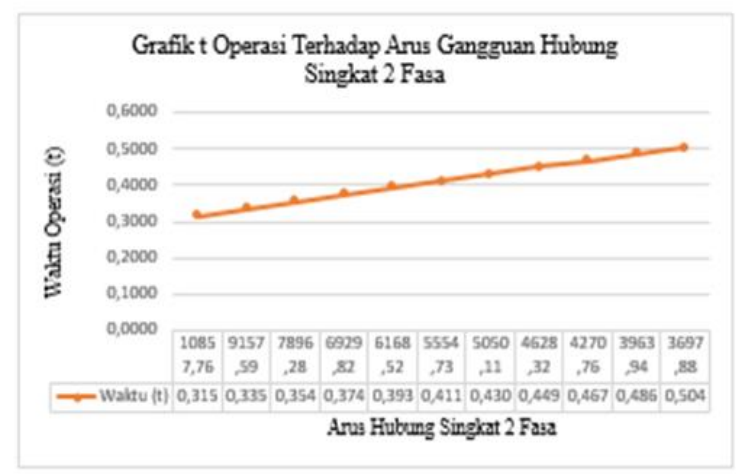

Gambar 4. Gambar grafik t Operasi terhadap Ihs 2 Fasa

Berdasarkan hasil perhitungan pemeriksaan waktu kerja (t) OCR outgoing terhadap besarnya arus gangguan hubung singkat dengan presentase jarak 0\% hingga 100\% dapat dilihat jika besarnya arus gangguan hubung singkat akan mempengaruhi waktu kerja ( $t)$ OCR outgoing. Untuk pemeriksaan waktu kerja (t) dari OCR outgoing, pada saat arus gangguan hubung singkat 3 fasa sebesar 12537,46 Ampere presentase jarak $0 \%$ waktu operasi ( $\mathrm{t}$ ) pada OCR outgoing adalah sebesar 0,3 detik. Sedangkan saat arus gangguan hubung singkat 3 fasa sebesar 4269,95 Ampere yakni pada presentase jarak $100 \%$ waktu kerja (t) pada OCR outgoing adalah sebesar 0,467 detik. Pemeriksaan waktu kerja (t) dari OCR outgoing terhadap besarnya arus gangguan hubung singkat 2 fasa saat arus gangguan hubung singkat 2 fasa sebesar 10857,76 Ampere presentase jarak $0 \%$ waktu kerja (t) pada OCR outgoing sebesar 0,315 detik. Sedangkan saat arus gangguan hubung singkat 2 fasa sebesar 3697,88 Ampere presentase jarak $100 \%$ waktu kerja (t) pada OCR outgoing sebesar 0,504 detik.

Hal ini menunjukkan bahwa waktu kerja (t) dari OCR outgoing dipengaruhi oleh nilai arus gangguan hubung singkat. Semakin besar nilai arus gangguan hubung singkat maka akan semakin cepat OCR outgoing untuk beroperasi dan semakin kecil nilai arus gangguan hubung singkat maka waktu kerja (t) dari OCR outgoing akan semakin lambat. Sedangkan besar kecilnya arus gangguan hubung singkat dipengaruhi oleh impedansi saluran/ penyulang dengan presentase jarak, dimana nilai impedansi $\mathrm{Z}$ berbanding terbalik dengan nilai arus I.

\section{- Waktu Kerja Recloser Saat Gangguan 3 Fasa dan 2 Fasa}

Pemeriksaan waktu kerja recloser (pemutus balik otomatis) dengan arus gangguan hubung singkat 3 fasa dan 2 fasa akan dilakukan perhitungan untuk mencari nilai waktu kerja pada recloser (pemutus balik otomatis) dengan presentase arus gangguan hubung singkat pada saat gangguan terjadi pada titik jarak $0 \%$ dan $100 \%$.

Gangguan hubung singkat 2 fasa titik jarak 1,99 km sebagai letak REC RB1-32

$$
\begin{aligned}
\mathrm{t} & =\frac{0,14 \times \mathrm{TMS}}{\left[\frac{\text { Ihs } 3 \emptyset}{\text { Iset }}\right]^{0,02}-1} \\
& =\frac{0,14 \times 0,10}{\left[\frac{7332,75}{240}\right]^{0,02}-1} \\
& =0,198 \mathrm{~s}
\end{aligned}
$$

Gangguan hubung singkat 3 fasa titik jarak 1,99 km sebagai letak REC RB1-32

$$
\begin{aligned}
\mathrm{t} & =\frac{0,14 \times \mathrm{TMS}}{\left[\frac{\text { Ihs } 3 \emptyset}{\text { Iset }}\right]^{0,02}-1}=0,207 \mathrm{~s} \\
& =\frac{0,14 \times 0,10}{\left[\frac{6350,35}{240}\right]^{0,02}-1} \\
& =0,207 \mathrm{~s}
\end{aligned}
$$

Tabel 8. Waktu Kerja Recloser Pada Gangguan 3 dan 2 fasa

\begin{tabular}{c|cc}
\hline \multirow{2}{*}{$\%$ Titik Jarak } & \multicolumn{2}{|c}{ Pemeriksaan Waktu Kerja Recloser (t) } \\
\cline { 2 - 3 } & $\begin{array}{c}\text { Gangguan 3 } \\
\text { Fasa }\end{array}$ & Gangguan 2 Fasa \\
\hline 0 & - & - \\
10 & - & - \\
20 & - & - \\
\hline
\end{tabular}




\begin{tabular}{ccc}
\hline 30 & - & - \\
REC RB1-32 & 0,198 & 0,207 \\
40 & 0,2 & 0,209 \\
50 & 0,206 & 0,216 \\
60 & 0,212 & 0,223 \\
70 & 0,219 & 0,230 \\
80 & 0,225 & 0,236 \\
90 & 0,231 & 0,243 \\
100 & 0,236 & 0,249 \\
\hline
\end{tabular}

Recloser (REC RB1-32 ) pada Gardu Induk $150 \mathrm{KV}$ Rembang yang terletak pada jarak $1,99 \mathrm{~km}$ memiliki nilai waktu kerja 0,198 detik pada saat terjadi gangguan hubung singkat 3 fasa dan saat terjadi gangguan hubung singkat 2 fasa waktu kerja pada recloser sebesar 0,207 detik.

\section{KESIMPULAN}

Berdasarkan hasil dari analisa yang dilakukan pada bab sebelumnya tentang "Analisa Koordinasi Setting Proteksi Over Current Relay (OCR) outgoing $20 \mathrm{KV}$ dan recloser feeder RBG 01 Trafo II 60 MVA di Gardu Induk $150 \mathrm{KV}$ Rembang", maka penulis dapat mengambil kesimpulan sebagai berikut:

1. Cara memperbaiki kondisi koordinasi proteksi di feeder RBG 01 ialah dengan melakukan resetting koordinasi OCR outgoing $20 \mathrm{KV}$ dan recloser sesuai kapasitas daya trafo II terpasang yakni 60 MVA karena pada Gardu Induk 150 KV Rembang mengalami perubahan perangkat berupa pergantian trafo II dari yang berkapasitas daya 30 MVA menjadi 60 MVA.

2. Hasil analisa koordinasi setting proteksi OCR outgoing $20 \mathrm{KV}$ dan recloser didapatkan nilai berikut ini :

a. Hasil resetting yang berdasarkan daya trafo II terpasang (60 MVA) arus hubung singkat 3 fasa dan 2 fasa pada jarak $0 \%$ masing-masing sebesar 12537,46 A dan 10857,76 A. Kondisi existing yang dipakai dilapangan dengan berdasar daya trafo II sebelum pergantian (30 MVA) arus hubung singkat 3 fasa dan 2 fasa pada jarak 0\% masing-masing sebesar 7914,32 A dan 6854,01 A.

b. Hasil resetting relai arus lebih (OCR) outgoing $20 \mathrm{KV}$ memiliki perbedaan nilai TMS dan Iset dengan hasil existing, resetting TMS OCR $=0,135$ dan existing TMS OCR $=$ 0,228 detik, sedangkan resetting Iset OCR $=$ 585 A dan existing Iset $\mathrm{OCR}=480 \mathrm{~A}$.

c. Hasil resetting pada recloser memiliki perbedaan nilai TMS dan Iset dengan hasil exist- ing, resetting TMS recloser $=0,120$ dan existing TMS recloser $=0,10$ sedangkan resetting Iset $\mathrm{OCR}=240 \mathrm{~A}$ dan existing Iset OCR $=400 \mathrm{~A}$.

3. Waktu kerja (t) OCR outgoing $20 \mathrm{KV}$ dan recloser feeder RBG 01 sebesar 0,3 detik dan 0,198 detik telah memenuhi standar penentuan antar peralatan proteksi saat terjadi gangguan maksimum IEC 60255 yaitu sebesar 0,3-0,5 detik untuk relai outgoing dan recloser harus lebih kecil dari relai outgoing.

4. Dikarenakan hasil resetting waktu kerja (t) OCR outgoing dan recloser sesuai standar IEC 60255 maka diharapkan kinerja dari OCR outgoing dan recloser dapat lebih peka dan selektif dalam memilih daerah yang harus diisolir saat terjadi gangguan

\section{DAFTAR PUSTAKa}

[1] J. Stevenson, William D., Analisa Sistem Tenaga, Ed.4. Malang: Lembaga Penerbitas Universitas Brawijaya, 1983.

[2] W. Sarimun, Proteksi Sistem Distribusi Tenaga Listrik, Edisi Pert. Depok: Garamond, 2012.

[3] A. Syafi'i, "Analisa Koordinasi Recloser dan OCR (Over Current Relay) untuk Gangguan Hubung Singkat Pada Penyulang 3 Distribusi $20 \mathrm{KV}$ GI JAJAR,” 2018.

[4] A. Ramadani, "Analisa Koordinasi Recloser Dan OCR (Over Current Relay) Untuk Hubung Singkat Pada Penyulang 9 Distribusi 20 KV GI BAWEN," 2018.

[5] D. Suswanto, Sistem Distribusi Tenaga Listrik, Edisi Pert. Padang, 2009.

[6] IEC 60255, Over Current Protection For Phase and Earth Fault.

[7] K. H. Bono, "Analisa Penggunaan Recloser 3 Phasa $20 \mathrm{kV}$ untuk Pengaman Arus Lebih Pada SUTM 20 kV Sistem 3 Phasa 4 Kawat di PT. PLN (PERSERO) APJ Semarang," pp. 1-8, 2005.

[8] SPLN 52-3, Pola Pengamanan Sistem: Sistem Distribusi $6 \mathrm{kV}$ dan $20 \mathrm{kV}$. Jakarta: Departemen Pertambangan \& Energi Perusahaan Umum Listrik Negara, 1983.

[9] T. R. Tri Aji, "PROTEKSI TEGANGAN LEBIH PADA GENERATOR MENGGUNAKAN OVER VOLTAGE RELAYDI JOB PERTAMINA TALISMAN JAMBI MERANG,” 2017. 